\title{
Rice Husk Ash as a Supplementary Raw Material for the Production of Cellulose-Cement Composites with Improved Performance
}

\author{
Conrado de Souza Rodrigues · Khosrow Ghavami • \\ Piet Stroeven
}

Received: 17 September 2009/Accepted: 15 March 2010/Published online: 13 April 2010

(C) The Author(s) 2010. This article is published with open access at Springerlink.com

\begin{abstract}
Rice husk is an agricultural by-product worldwide in large quantities available. This is a suitable biomass source for energy production. Compared to other agricultural by-products, the burned rice husk presents a high yield of ash (about 20\%) mainly composed of silica that will be mostly amorphous when properly incinerated. Extensive research in the past three decades has allowed the introduction of rice husk ash (RHA) as a supplementary raw material in cement-based products, whereby significant improvements in strength and durability can be achieved, also contributing to ecological demands. This paper investigates the influences of two RHA admixtures on the physical and mechanical properties of bamboo-pulp-reinforced cement composites. These fibers suffer early degradation in the alkaline environment. RHA blending will reduce the ordinary Portland cement (OPC) content and can improve strength and density due to more effective particle packing, and significantly diminish alkalinity. The composites were produced in the laboratory by a method
\end{abstract}

C. de Souza Rodrigues $(\bowtie)$

Civil Engineering Department, Federal Centre for Technological Education in Minas Gerais (CEFET-MG), Av Amazonas, 7675, CEP 30510-000 Belo Horizonte, MG, Brazil

e-mail: crodrigues@civil.cefetmg.br

\section{K. Ghavami}

Civil Engineering Department, Pontifical Catholic University in Rio de Janeiro (PUC-Rio), Av. Marquês de São Vicente, 225, CEP 22453-900 Rio de Janeiro, RJ, Brazil

e-mail: ghavami@puc-rio.br

\section{P. Stroeven}

Faculty of Civil Engineering and Geosciences, Delft University of Technology (TUDelft), Stevinweg 1, 2628 CN Delft,

The Netherlands

e-mail: p.stroeven@tudelft.nl resembling the Hatschek process used by the fibrocement industry, with fixed reinforcement content and varying amounts of RHA. The results revealed that partial replacement of ordinary Portland cement by up to $30 \%$ of RHA had not impaired the mechanical behavior of the composites. Further, use of low-carbon-content RHA decreased porosity in the matrix and enhanced interfacial bonding of the composites. Since the deterioration of cellulose-cement composites is closely related to moisture movement and alkalinity, it is concluded that introduction of low-carbon content RHA can lead to improved durability performance of these composites.

Keywords Agricultural residues - Asbestos replacement . Bamboo pulp · Mechanical behavior - Mineral admixtures . Pore structure

\section{Introduction}

RHA as A Mineral Admixture in Cement-Based Materials

Rice is a major crop in many world regions, accounting for an estimated production of rice husk as an agricultural residue of about 650 million tones in 2007 [1]. When applied as biomass for energy production, this amount of rice husk would yield about 130 million tones of ash with silica contents typically above $90 \%$. When the burning process is carried out properly-regarding the burning temperature and the cooling rate, the silica in the RHA is mainly amorphous. Sufficient grinding of RHA allows the dissolution of the silica in the highly alkaline environment of the cement paste and its reaction with $\mathrm{Ca}(\mathrm{OH})_{2}$. The pozzolanic reactivity is generally considered a key factor 
for selecting mineral admixtures for blending cementbased components, because of improving major material properties like strength and durability [2-4]. Fineness of the mineral admixture also affects chemical as well as physical properties of the matured material [5].

During the last three decades much has been contributed to the processing of rice husks, as well as to the characterization of RHA, besides many case studies which have been performed. Detailed information is now available on the effects of the incineration process on the properties of RHA [6, 7]. As a result, pilot plants have been designed and operate for processing rice husks for the use as mineral admixtures [3, 8]. At present time RHA can be regarded, according to Taylor [9] and Mehta and Monteiro [10], as an established highly reactive mineral admixture for partial cement replacement in concrete, mortar and cement paste; as well as silica fume. All these studies set the basis for the production of highly reactive pozzolanic materials from other agricultural by-products, such as the sugar cane bagasse ash resulting from the production of ethanol in Brazil [11].

\section{Mineral Admixtures in Cellulose-Cement Composites}

Among the wide range of available fibers with potential for asbestos replacement in cement composites, cellulosic pulps have always being considered a viable substitute. Still, physical and chemical properties of the matrix, as well as the production process of the composites have to be attuned to this application [12]. As a matter of fact, cellulosic pulps have already been applied as reinforcement in large scale production of cement-based composites for the last 30 years [13]. These non-hazardous composites present short-term mechanical and physical behavior compatible to that observed in asbestos-cement for most common applications. However, durability performance of the developed composites still demands further research efforts.

Environmental effects due to moisture and heat variations, combined with OPC hydration products, activate a range of mechanisms in the high alkalinity environment of the cementitious matrix that modify the properties of the cellulose-cement composites, impairing their long term performance. These mechanisms are described in detail in the literature [14, 15] and specifically concern the composite's strength loss due to:

(a) interfacial debonding, because of fiber-matrix interface abrasion resulting from expansion-shrinkage cycles of fibers and matrix subjected to temperature and moisture variations;

(b) fiber embrittlement, resulting from the migration of hydration products to the fibers' pores and lumen; (c) alkali attack through dissolution of the cellulosic chain by some hydration products, leading to fiber deterioration.

These deterioration mechanisms are governed by the moisture movement through the porous network of composites. Therefore, one of the approaches for the development of composites with improved durability performance is the matrix modification by partial replacement of ordinary Portland cement (OPC) by finely ground reactive mineral admixtures with high silica content.

Durable cellulose-cement composites can be obtained at low matrix alkalinity and reduced porosity and permeability of the matrix and interfaces [14, 15]. The incorporation of mineral admixtures in cement-based materials results in chemical and physical effects of interrelated nature. The pozzolanic reaction can be understood in chemical terms as a dissolution-precipitation mechanism, yielding reaction products smaller in size than the original admixture and cement particles [16]. Therefore, besides the decreased alkalinity of the matrix by the $\mathrm{Ca}(\mathrm{OH})_{2}$ consumption in the pozzolanic reaction, the finer un-reacted particles as well as the reaction products fill the pores in matrix and at interfaces, reducing the composite's overall porosity and permeability, leading to improved strength and lower susceptibility to the deterioration. The filling effect can exceed that of the pozzolanic reactivity of the admixture, as shown by Goldman and Bentur [17] in experiments on concrete and mortar based on cement blended with inert carbon black.

Durability performance of cellulose-cement composites has been studied as function of alkali content and permeability of the matrix by MacVicar et al. [14]. They have shown that accelerated carbonation of the composite samples after curing results in lower porosity and permeability, allowing a better performance when the composites were subjected to accelerated weathering cycles. On the other hand, durable composites were also obtained when produced with a $\mathrm{Ca}(\mathrm{OH})_{2}$-free matrix. This was achieved by means of high replacement rates of cement by mineral admixtures [15-17].

\section{Research Significance}

RHA is applied in this study as a partial replacement material for OPC in cellulose-cement composites as a means to obtain cementitious materials with improved structure and properties, i.e., accomplished by denser and thus less permeable matrices and interfaces. The effects of RHA on the composites' structure and their properties will be evaluated considering the pore structure, the results of the bending tests and also the evaluation of the composites interfaces with scanning electron microscopy (SEM). 


\section{Methodology}

Raw Materials and Composite Production

Since RHA properties are very sensitive to the burning process, ashes with different chemical compositions resulted from different burning conditions were considered in this study. A high-carbon-content RHA, representing ashes resulting from poorly controlled processes, was obtained from rice husks burned at temperatures ranging from 500 to $750^{\circ} \mathrm{C}$ in a fluidized bed kiln specially developed for this purpose [4]. This ash is denoted by RHA-I. A low-carbon-content ash, RHA-II, was obtained by re-burning part of RHA-I during $3 \mathrm{~h}$ in a conventional muffle kiln at $750^{\circ} \mathrm{C}$. Both ashes were ground in a ceramic ball mill for $12 \mathrm{~h}$. The chemical and physical properties of the two ashes are presented in Table 1.

Pozzolanic activity is defined by measuring the change in electrical conductivity in $\Delta \mathrm{mS} / \mathrm{cm}$ of a saturated lime solution due to RHA addition [18]. The specific surface area, $\mathrm{S}_{\mathrm{BET}}$, was established by $\mathrm{N}_{2}$ absorption and the average particle size of the ashes, $\delta$, was obtained from the particle size distribution, established by the Coulter Counter method [19].

The Kraft unbleached bamboo pulp, provided by a paper production plant located in the Northeast part of Brazil, presents cellulosic fibers with average length of $1.5 \mathrm{~mm}$ and diameter of about $20 \mu \mathrm{m}$. The composites were produced by the slurry mix vacuum-dewatering compaction method, which resembles on laboratory scale the industrial Hatschek process for the production of thin fibro-cement sheets [20]. Different from the conventional mixing applied in the production of cement-based materials, the Hatschek process allows the use of high reinforcement rates, once the slurry mixing, with about $20 \%$ of solids and without a fixed

Table 1 Composition and physical properties of RHA and OPC

\begin{tabular}{llll}
\hline & RHA-I & RHA-II & OPC \\
\hline $\mathrm{SiO}_{2}(\%)$ & 73.60 & 94.60 & 17.90 \\
$\mathrm{C}(\mathrm{LOI})(\%)$ & 22.90 & 1.40 & 1.60 \\
$\mathrm{Al}_{2} \mathrm{O}_{3}(\%)$ & 0.075 & 0.09 & 4.85 \\
$\mathrm{Fe}_{2} \mathrm{O}_{3}(\%)$ & 0.26 & 0.15 & 2.70 \\
$\mathrm{MgO}(\%)$ & 0.27 & 0.28 & 2.15 \\
$\mathrm{CaO}(\%)$ & 0.76 & 0.93 & 64.45 \\
$\mathrm{Na}_{2} \mathrm{O}(\%)$ & 0.09 & 0.06 & 0.30 \\
$\mathrm{~K}_{2} \mathrm{O}(\%)$ & 1.17 & 1.12 & - \\
$\mathrm{SO}_{3}(\%)$ & - & - & 2.40 \\
$(\Delta \mathrm{mS} / \mathrm{cm})^{\mathrm{a}}$ & 1.40 & 0.58 & - \\
$S_{\mathrm{BET}}\left(\mathrm{m}^{2} / \mathrm{g}\right)^{\mathrm{b}}$ & 119 & 15 & 1.89 \\
$\delta(\mu \mathrm{m})^{\mathrm{c}}$ & 1.8 & 4.0 & 10 \\
\hline
\end{tabular}

$\overline{{ }^{a} \text { Pozzolanic activity, }{ }^{\mathrm{b}} \text { Specific surface area, }{ }^{\mathrm{c}} \text { Average particle size }}$ water/cement ratio, provides a convenient dispersion of the fibers and matrix. Optimum reinforcement rates for achieving higher bending strength depend on the pulp source. In most of the cases in which hard- and softwood pulp and non-wood pulp are involved, the higher bending strengths are obtained at reinforcement rates between 8 and $12 \%$ by weight of the cementitious material employed [13, 20]. In the present study a fixed reinforcement rate of $8 \%$ by weight of the cement was selected. The OPC applied is compatible with ASTM type I; compositional details are provided in Table 1.

Previous studies have shown that a complete consumption of $\mathrm{Ca}(\mathrm{OH})_{2}$ in the hydrated cement paste is achieved when partial cement replacement rates were applied between $10 \%$ and more than $50 \%$, depending on the mineral admixture considered [21, 22]. Relying on the fact that RHA is regarded as a highly reactive pozzolanic material $[9,10]$, a replacement rate of $15 \%$ is expected to lead to a significant reduction in free lime content. A replacement rate of $30 \%$ was also applied. Since the RHA is finer than the cement, densification of matrix and interfaces could be expected due to the filler effect of the non-reacted particles.

Composite plates were produced measuring $120 \mathrm{~mm} \times$ $120 \mathrm{~mm}$ with a thickness varying from 6 to $8 \mathrm{~mm}$ (depending on the composition of the mix). The blended cement composites are designated as, CP30-II, where the number after "CP" refers to the RHA content and type. The composites were cured in a sealed plastic bag for 1 week, and exposed to the open air for the rest of the curing period of 28 days. Plain matrices were also cast by the same production method to evaluate effects exerted by the cellulosic reinforcement on the pore structure. Only RHA-I was used in these blended-cement pastes sheets.

\section{Composites Characterization}

The mechanical parameters of the composites were established following the recommendations of the RILEM Technical Committee 49 TFR [23]. For the bending tests, the composite plates were sawn into three specimens of $38 \mathrm{~mm} \times 120 \mathrm{~mm}$. Thickness varied between 6 and $8 \mathrm{~mm}$, depending on the composition of the mix. The three point bending tests were performed on an Instron 5500-R servocontrolled universal testing machine with a loading rate of $0.5 \mathrm{~mm} / \mathrm{min}$. Six samples were prepared for each composite mix. Further, tests were carried out on samples with two moisture conditions, due to the sensitivity of mechanical properties of cellulose-cement composites to such conditions. Composites were considered in equilibrium when stored for five days before the tests in controlled environment conditions $\left(50 \%\right.$ R.H., $\left.23^{\circ} \mathrm{C}\right)$; saturated samples were soaked in water for 2 days before being tested. 
Bending strength of the composites $\sigma_{\mathrm{b}}(=\mathrm{MOR})$ was defined by the maximum of the load $(P)$-displacement $(\delta)$ curve according to Eq. 1

$\sigma_{b}=\frac{3 P S}{2 b t^{2}}$

where $S, b$ and $t$ are the span $(100 \mathrm{~mm})$, width $(38 \mathrm{~mm})$ and thickness of the specimen, respectively. The energy absorption or flexural toughness equals the area under the $P-\delta$ curve. When normalized by the cross sectional area of the specimen this yields the Specific Energy, EE $\left(\mathrm{KJ} / \mathrm{m}^{2}\right)$. The flexural stiffness (MOE in GPa) is obtained from Eq. 2

$\mathrm{MOE}=\tan (\Theta) \frac{S^{3}}{4 b t^{3}}$

where $\tan (\Theta)$ presents the slope of the linear branch of the curve. The limit of proportionality (LOP in MPa) characterizes the maximum stress of the initial linear part of the curve.

The pore structure of the composites was studied by MIP (Mercury Intrusion Porosimetry), whereby the pore size distribution is derived from the relationship between pore diameter and pressure applied to the mercury intruding the sample. The so called Washburn equation, Eq. 3 $[24,25]$,

$d=\frac{-4 \cdot \gamma \cdot \cos \theta}{P}$

permits to estimate the diameter $(d)$ of assumed cylindrical pores intruded at each pressuring step. Values of $\gamma=485$ dyn $/ \mathrm{cm}^{2}(0.1 \mathrm{~Pa})$ and $\theta=141^{\circ}$ were adopted in Eq. 3. For comparative purposes, the intrusion volume values are expressed in percentage of the bulk volume of the sample. The samples were composed of several pieces taken from two different plates of similar composites. Tests were performed 6 months after the composites' production by a Micromeritics Pore Sizer 9320 with pressure varying from 0 to $205 \mathrm{MPa}$, which corresponds to a pore range of 0.007 to $300 \mu \mathrm{m}$ for the material considered.

The comparison among the different pore structures of the involved composites is carried out considering two complementary curves. The incremental intrusion curve reflects the volume of $\mathrm{Hg}$ intruded in the sample in each of the successive steps. The total volume of $\mathrm{Hg}$ intruded in the sample at a given pressure is given by the cumulative intrusion curve. Therefore, at the maximum pressure applied, the curve indicates that part of the sample's porosity which is accessible by the $\mathrm{Hg}[25,26]$. It should be noted that MIP, although widely used for porosimetry, provides pore characteristics significantly different from more realistic image analysis approaches [25]; hence application should be restricted to comparing effects of technological or production parameters, as accomplished in this paper.
The complementary analysis of the composites with RHA was carried out by scanning electron microscopy (SEM), in which the main focus was on the fiber-matrix interfaces. The samples were obtained from the specimens used in the mechanical tests. Small parts of these specimens were sawn and broken perpendicularly to the specimen thickness. This is because the vacuum dewatering-compaction method employed in the composites' production results in fibers randomly oriented in the plane of the plates. Therefore, it was expected that the rupture of the composite perpendicular to its thickness would reveal well the interfaces for the evaluation.

\section{Results and Discussion}

\section{RHA Characterization}

Chemical compositions of RHA-I and RHA-II composites basically differ in the amounts of carbon and silica. The prolonged burning applied to RHA-II decreased the carbon content from 22.9 to $1.4 \%$, with an equivalent increase in the amount of silica. This change in the composition has affected all the physical properties investigated. Firstly, the carbon-rich RHA-I is softer than RHA-II. This led to smaller particles at the same grinding energy as shown in Fig. 1. In turn this reveals that both ashes are finer than the ordinary portland cement (OPC).

The carbon in the carbon-rich RHA-I is reported to be very porous $[2,3]$. The silica in the RHA particles is generally also very porous, unless grinded down to sizes comparable to pore spacing in the RHA particles [5]. RHAI is probably closer to this condition than RHA-II. Hence, the large specific surface area in RHA-I is due to the inert carbon and the silica content of the ash, whereas the specific surface area is the result of the highly pozzolanic but

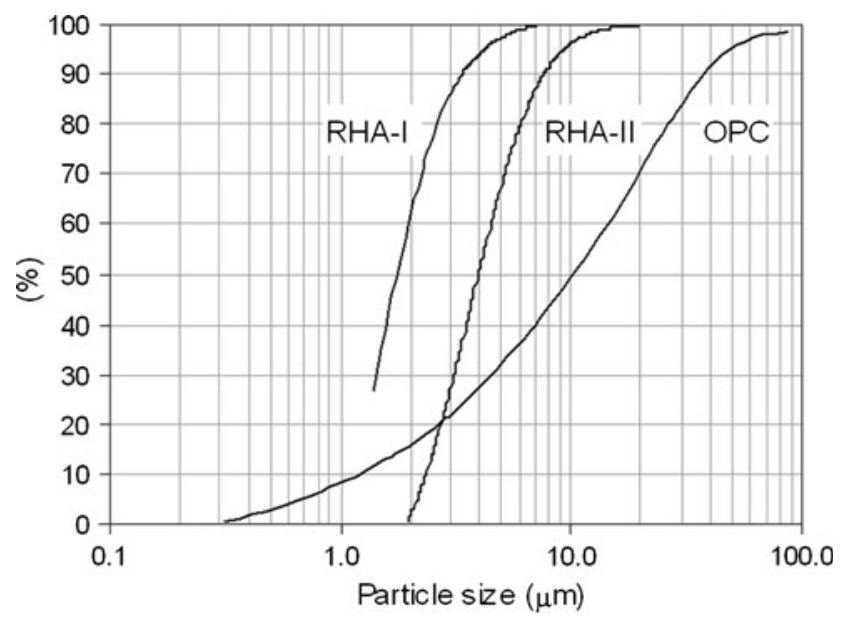

Fig. 1 Particle size distribution of RHA and OPC 
porous silica in RHA-II. Since RHA particle size is not very small, the specific surface area of RHA-II particles is only of a moderate level. Further grinding would have initially increased this value, before the aforementioned drop occurs when particle size approximates pore spacing [4]. The prolonged incineration period applied to RHA-II removed most of the carbon and may have somewhat modified the surface of the particles. As a consequence of these mechanisms, RHA-II presents lower specific surface area and larger particles after being grinded for the same period as RHA-I. Only part of the larger specific surface area of RHA-I is however due to the pozzolanic material.

The lower specific surface area of RHA-II has as direct effect on the pozzolanic activity established by the changes in electrical conductivity of a saturated lime solution. Particles with higher $S_{\mathrm{BET}}$ values quickly attract the $\mathrm{Ca}^{2+}$ ions, resulting in a faster change in the conductivity. Therefore, due to its higher $S_{\mathrm{BET}}$ values, RHA-I falls into the high pozzolanicity group by the classification proposed in Luxán et al. [21], while RHA-II presents moderate pozzolanic activity.

\section{Composites’ Mechanical Properties}

The mechanical parameters of the composites and the nonreinforced cement pastes are presented in Table 2. The incorporation of 15 and $30 \%$ of RHA-I in cement pastes reduced bending strength and stiffness, more at higher partial cement replacement, whereas no significant effect was observed for RHA-II composites. Strength reduction can be attributed to lower active binder components in RHA-I mixtures, because of the significant carbon content. Carbon has also a relatively low stiffness, so causes the decline in plain matrix stiffness.

Comparing matrix and composites without RHA, it can be concluded that the addition of fibers resulted in a significant increase in MOR and decrease in MOE. The first reflects the fiber-matrix interaction after the matrix cracking and the second is due to the relatively low stiffness of the fibers and the additional porosity at the fiber-matrix interfaces.

It is well-known that saturation in water reduces strength and stiffness of specimens of cementitious materials significantly. Water has an additional detrimental effect on the strength of the cellulosic fibers and on interfacial bond [13]. This effect of water saturation is confirmed by the overall observations in this study. Strength of reinforced specimens reduced to lower than that of plain specimens when compared to the saturated tested composites. As far as the excess of moisture prevents the interaction between fibers and matrix [13, 20], the composite behavior of equilibrium samples is replaced by an increased porosity (unbounded fibers) in the saturated composites. The effect of water saturation in CP30-I is negligible as the high amount of high carbon content ash already resulted in composite with low bending strength in equilibrium condition.

A proposal for the determination of interfacial adhesion strength in cellulose-cement composites, reflecting the influence of RHA on this property, can be found in [27]. Following this approach, the pre-crack adhesion strength of composites without admixture, $\mathrm{CP} 0$, was found to be $0.54 \mathrm{MPa}$, while this adhesion strength amounted 0.75 and $0.94 \mathrm{MPa}$, respectively, for the composites with 15 and $30 \%$ RHA-II. On the other hand, the replacement of 15 and $30 \%$ OPC by RHA-I decreased the adhesion strength to 0.33 and $0.07 \mathrm{MPa}$, respectively.

\section{Pore Structure by MIP}

Intrusion curves reflecting the pore characteristics observed in MIP tests of unblended M0 (unreinforced) and CP0 (reinforced) specimens are shown in Fig. 2. A comparison of the results shows that pores larger than $0.15 \mu \mathrm{m}$ are responsible for the difference between these materials. While in the paste this pore range corresponds to about $8.5 \%$ of total porosity, in the composites they do so for almost 50\%. On the other hand, the pore size distribution of the paste and composite are very similar for pores smaller than $0.15 \mu \mathrm{m}$, proving that the addition of cellulosic pulp does not influence the matrix structure.

The cementitious matrix is characterized by high volume of $\mathrm{Hg}$ intruded in pores of $0.15 \mu \mathrm{m}$. This threshold pore diameter is one of the main features of the porous media. It is conceived as the diameter of the pore that completes the first interconnected pathway developed by a procedure of sequentially adding pores of diminishing size to this network. The smaller the critical pore size, the finer the pore structure [4, 28]. Similar characteristics as observed for $\mathrm{M} 0$ and $\mathrm{CP} 0$ were also recorded for pastes and composites with 15 and $30 \%$ of RHA-I.

The intrusion curves in Fig. 3 allow to compare the effects of the RHA-I addition on the pore structure of the composites. It is shown that porosity of the blended-cement composites reveals the same characteristics as those of the unblended composite, with all samples presenting total porosity of about $25 \%$. The main effect of RHA-I can be observed in pores smaller than $0.15 \mu \mathrm{m}$ that characterize the matrix. More specifically, the blended-cement composites show a significantly lower volume of pores with diameters between 0.05 and $0.15 \mu \mathrm{m}$, which due to the relatively small particles of RHA-I. The higher the replacement rate, the lower the porosity in this range.

The effects of the incorporation of RHA-II on the pore size distribution of the composites are shown in Fig. 4. The overall porosity slightly decreases with increasing RHA-II 
Table 2 Influence of RHA on the mechanical parameters of cement pastes and composites

\begin{tabular}{|c|c|c|c|c|}
\hline & $\mathrm{MOR}(\mathrm{MPa}) \pm \mathrm{SD}$ & $\mathrm{EE}\left(\mathrm{kJ} / \mathrm{m}^{2}\right) \pm \mathrm{SD}$ & $\mathrm{MOE}(\mathrm{GPa}) \pm \mathrm{SD}$ & $\mathrm{LOP}(\mathrm{MPa}) \pm \mathrm{SD}$ \\
\hline \multicolumn{5}{|c|}{ Unreinforced cement pastes } \\
\hline M0 (eq.) & $12.93 \pm 1.34$ & $0.05 \pm 0.01$ & $19.21 \pm 1.51$ & \\
\hline M15-I (eq.) & $14.72 \pm 1.20$ & $0.07 \pm 0.01$ & $15.90 \pm 0.98$ & \\
\hline M30-I (eq.) & $13.32 \pm 1.46$ & $0.07 \pm 0.01$ & $14.85 \pm 0.61$ & \\
\hline \multicolumn{5}{|c|}{ Cement composites } \\
\hline CP0 (eq.) & $15.53 \pm 0.58$ & $0.34 \pm 0.04$ & $10.97 \pm 0.70$ & $12.85 \pm 1.45$ \\
\hline CP0 (sat.) & $9.66 \pm 0.76$ & $0.79 \pm 0.21$ & $7.31 \pm 0.75$ & $7.86 \pm 0.49$ \\
\hline CP15-I (eq.) & $14.61 \pm 0.75$ & $0.42 \pm 0.04$ & $9.85 \pm 1.06$ & $11.90 \pm 1.07$ \\
\hline CP15-I (sat.) & $11.75 \pm 1.24$ & $0.71 \pm 0.13$ & $8.35 \pm 1.66$ & $9.26 \pm 1.63$ \\
\hline CP30-I (eq.) & $11.86 \pm 0.79$ & $0.49 \pm 0.05$ & $7.37 \pm 0.48$ & $9.29 \pm 0.92$ \\
\hline CP30-I (sat.) & $10.84 \pm 0.48$ & $0.60 \pm 0.08$ & $8.64 \pm 0.66$ & $9.51 \pm 0.92$ \\
\hline CP15-II (eq.) & $15.31 \pm 1.08$ & $0.40 \pm 0.05$ & $9.40 \pm 0.90$ & $13.95 \pm 1.15$ \\
\hline CP15-II (sat.) & $9.23 \pm 0.29$ & $0.92 \pm 0.11$ & $6.95 \pm 1.35$ & $6.75 \pm 0.49$ \\
\hline CP30-II (eq.) & $16.51 \pm 1.02$ & $0.43 \pm 0.03$ & $10.34 \pm 0.31$ & $15.78 \pm 1.14$ \\
\hline sCP30-II (sat.) & $10.95 \pm 1.07$ & $1.24 \pm 0.19$ & $8.65 \pm 0.65$ & $6.66 \pm 0.35$ \\
\hline
\end{tabular}

Fig. 2 Intrusion curves of unreinforced cement paste (M0) and composite $(\mathrm{CP} 0)$

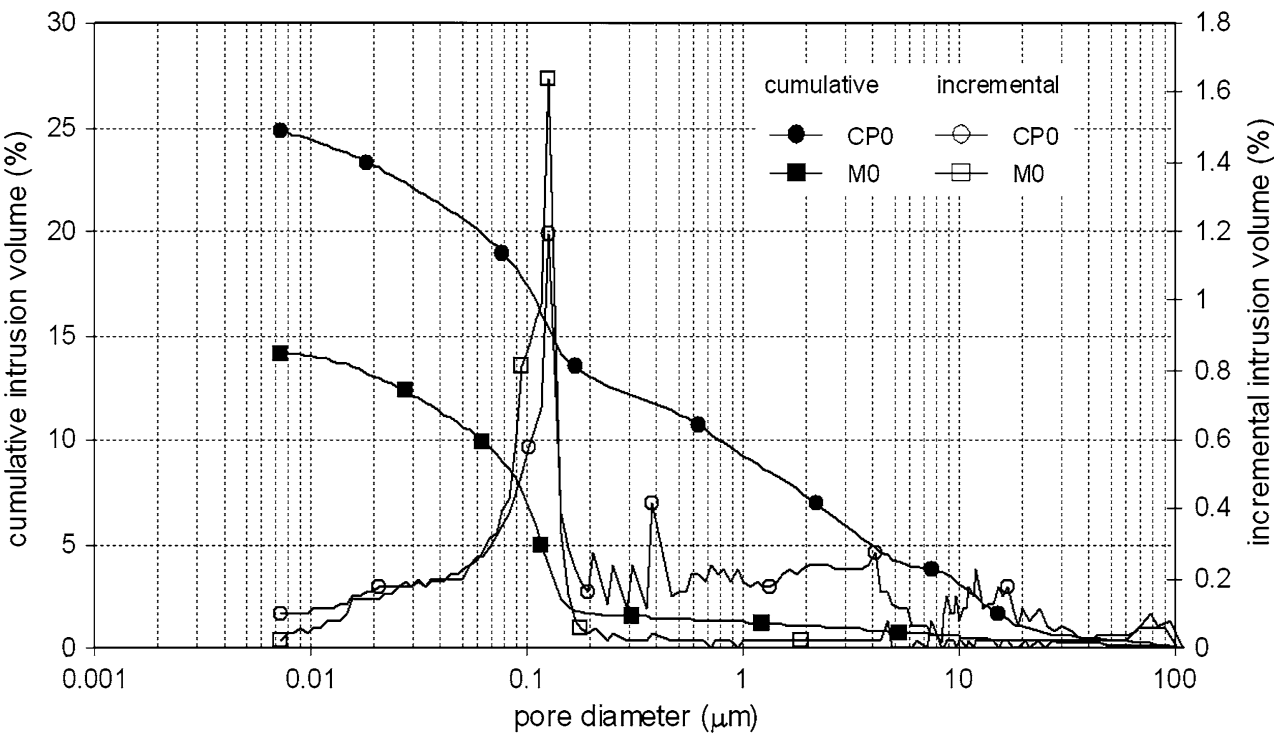

content. It can be observed that the only section of the incremental intrusion curve in which blended cement composites score higher than the plain-cement composite is for pores with diameters between 1 and $5 \mu \mathrm{m}$. From diameters of 1 to $0.4 \mu \mathrm{m}$ the incremental intrusion curves of the plain and blended cement composites follow at almost the same intrusion levels.

Composites with and without RHA-II show the most striking differences at the threshold diameter. Instead of the intrusion peak that characterizes the threshold diameter of the matrix, the blended-cement composites present intrusion levels remarkably lower, and at a significantly lower level than in the cases of RHA-I blended materials. The features observed in the intrusion curves of CP15-II and CP30-II reflect significant decreases in the matrix porosity of the composites and blocking of the interconnected pore network due to RHA-II incorporation.

Once RHA-II is composed by larger particles than RHA-I, the lower porosity in the matrix of the composites with RHA-II will probably be resulting from the higher activity and larger content of silica in the ash. Considering the pozzolanic reaction as a dissolution precipitation mechanism [16], RHA-II results in more reaction products filling the pores in the composite matrix. Once CP15-II presents lower matrix porosity than CP30-I, it indicates that the higher reactivity of RHA-II is not only due to its high silica content, but also reflects further improvements resulting from the controlled burning.

The relation between pore structure and permeability in cellulose cement composites is discussed in a previous 
Fig. 3 Intrusion curves of composites with RHA-I
Fig. 4 Intrusion curves of composites with RHA-II
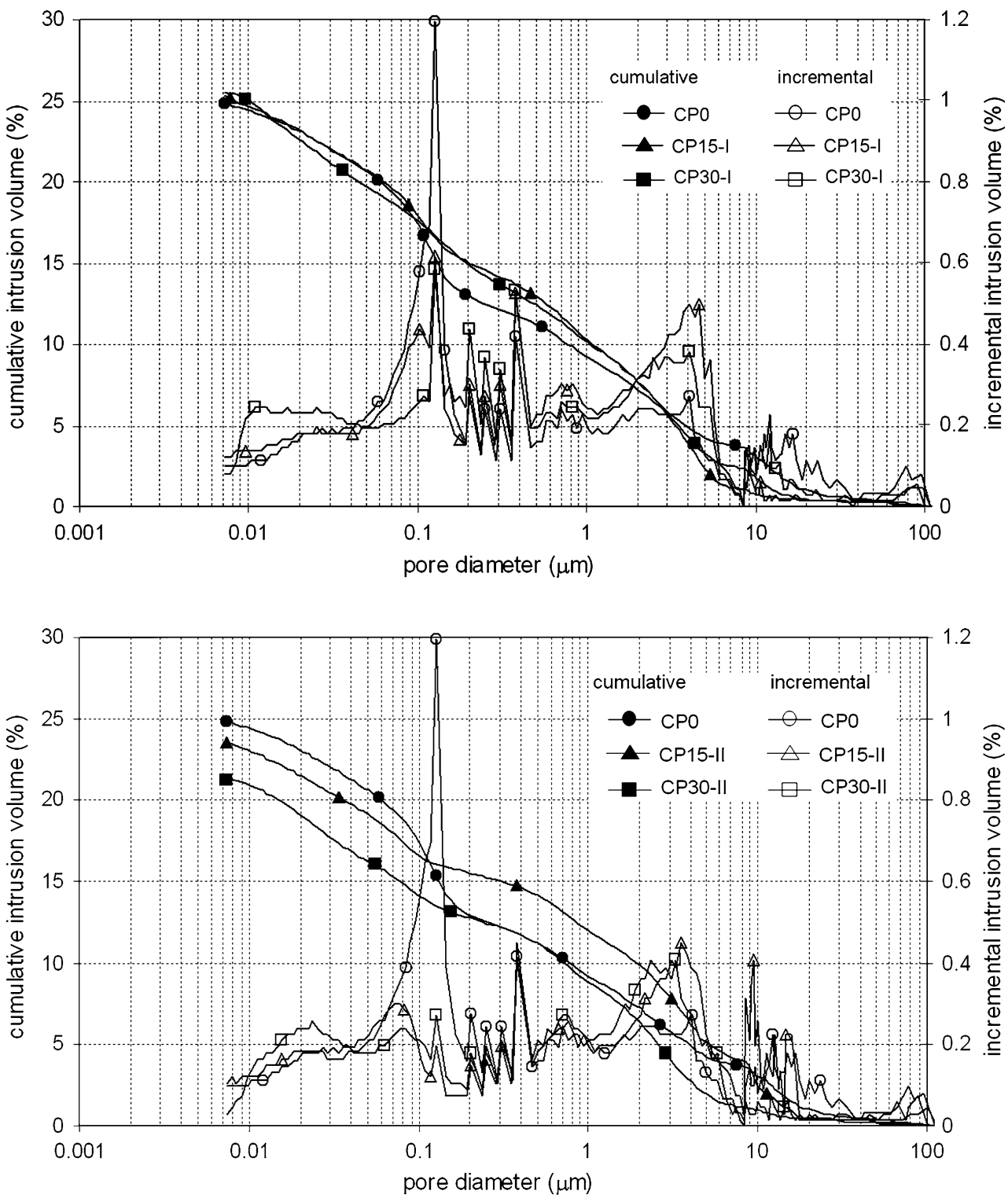

paper [29], where it was shown that the incorporation of RHA-II resulted in a significant decrease in the composites' water permeability (established experimentally in a diffusion cell). While the composite without RHA presented a coefficient of permeability $(K)$ of $21 \times 10^{-2} \mathrm{~m}^{2}$, the incorporation of $30 \%$ RHA-II resulted in $K=0.38 \times 10^{-2} \mathrm{~m}^{2}$. In turn the introduction of $30 \%$ RHA-I slightly increased the permeability coefficient to $K=38 \times 10^{-2} \mathrm{~m}^{2}$.

The higher pozzolanic activity of RHA-I indicated by the changes in the electrical conductivity of a saturated lime solution (Table 1) was not confirmed by the mechanical and MIP tests. Due to the high specific surface area of RHA-I, $\mathrm{Ca}^{2+}$ ions are quickly adsorbed on the surface of the particles. However, the high amount of carbon seems to prevent a proper development of the pozzolanic reaction. Moreover, the amount of active silica is reduced by the high carbon content. On the other hand, the low carbon content and higher amount of silica of RHA-II resulted in remarkable effects in composites strength and pore distribution, even considering its larger particles size and lower $S_{\mathrm{BET}}$ values.

\section{SEM Analysis}

Figures 5 and 6 present details of the interfaces of composites without admixture, CP0 (Fig. 5a and b), and with RHA-II, CP30-II (Fig. 6a and b). In the specimens CP0 the interfaces, indicated by the arrow in Fig. 5b, show rough surfaces, presenting extensive porosity and microcracking. Also a large amount of dispersed nail-like crystals (ettringite) can be observed. This feature is absent in the other 


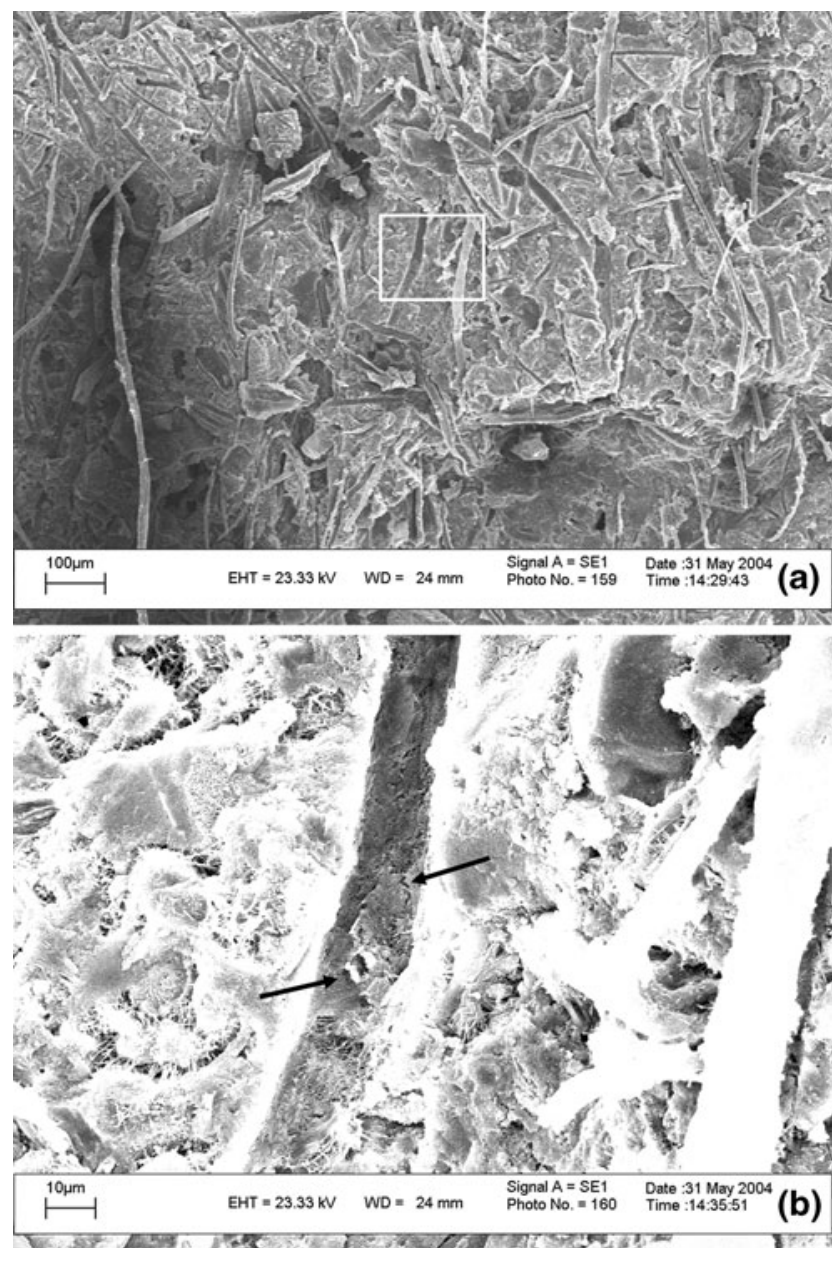

Fig. 5 General view (a) and detailed interface (b) in CP0

composites. In the specimens CP30-II, the interfaces pointed by the arrow in Fig. $6 \mathrm{~b}$ present smoother surfaces, with fewer discontinuities. The rougher surfaces observed in CP0 may be responsible for better mechanical interaction in the interface; however, the extensive porosity and microcracking may result in composites more susceptible to the main deterioration mechanisms.

\section{Conclusions}

The composites with RHA-I presented decreased porosity in the matrix, which is achieved due to the finer particles of this ash. However, the high carbon content in RHA-I prevent a proper interfacial adhesion between the matrix and the cellulose fibers, decreasing the composites' bending strength. This is also resulting from the associated relatively low silica content. Nevertheless, admixtures such as RHA-I can be properly employed in other cement based materials. When pore size is adjusted to that of the Portland
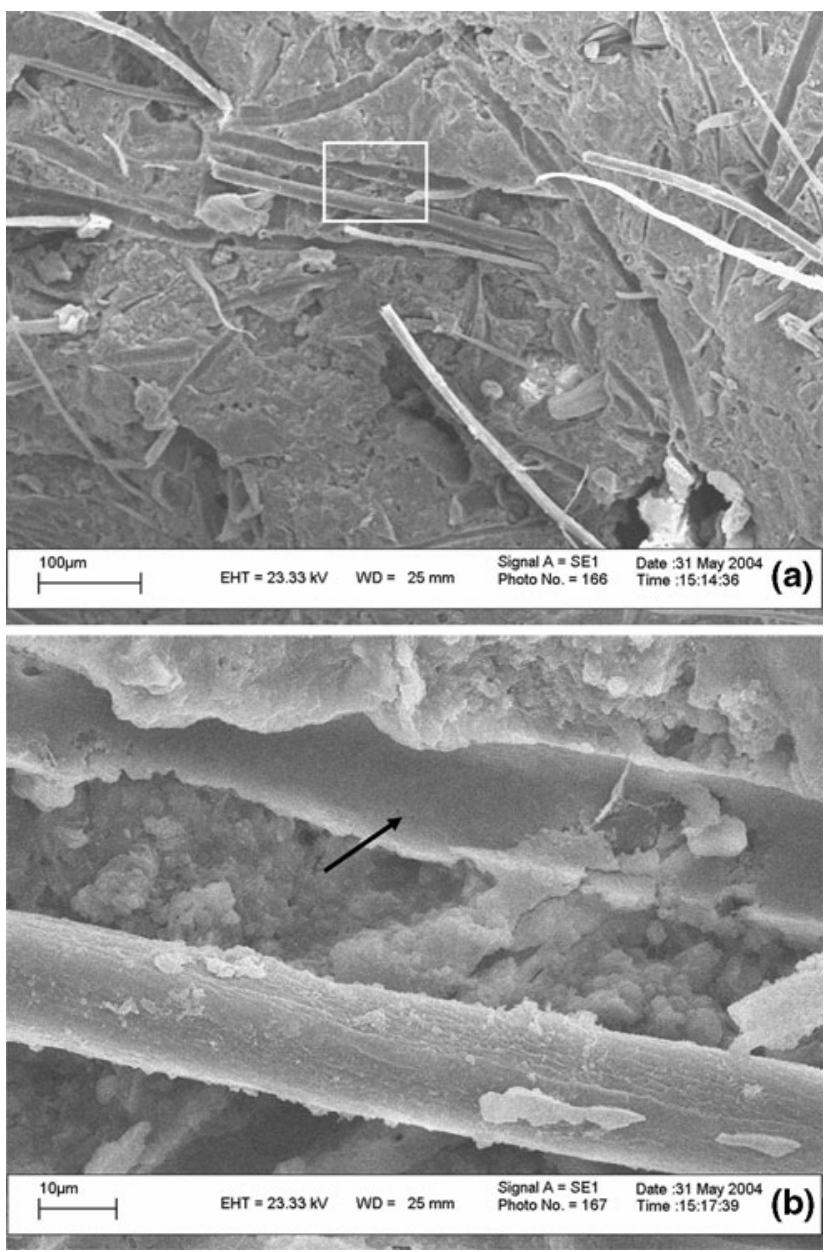

Fig. 6 General view (a) and detailed interface (b) in CP30-II

cement, strength and durability can be improving the same way as in [17].

The RHA-II, although composed by larger particles and with a lower specific surface area as compared with RHA-I, resulted in composites with enhanced structure and performance. The replacement of up to $30 \%$ of cement by RHA-II modified the pore structure, with the blocking of the interconnected pore network and leading to less permeable composites. Incorporation of RHA-II in the composites did not impair the bending strength and stiffness of the developed composites and improved their interfacial adhesion strength. With a lower permeability and higher interfacial adhesion strength, the composites with RHA-II present improved durability performance, considering the main deterioration mechanisms in cellulose-cement composites.

Acknowledgements Authors would like to thank for the financial support provided by the Brazilian national (CAPES, CNPq) and the State (FAPEMIG, FAPERJ) research agencies and the support of TUDelft for making this collaborative research possible. 
Open Access This article is distributed under the terms of the Creative Commons Attribution Noncommercial License which permits any noncommercial use, distribution, and reproduction in any medium, provided the original author(s) and source are credited.

\section{References}

1. FAOStat-FAO Statistics Division: http://faostat.fao.org (2009). Accessed 19 May 2009

2. Cook, D.J.: Rice Husk Ash. In: Swamy, R.N. (ed.) Concrete Technology and Design, vol. 3: Cement Replacement Materials, pp. 171-192. Blackie \& Son Ltd, London (1986)

3. Stroeven, P., Bui, D.D., Sabuni, E.: Ash of vegetable waste used for economic production of low to high strength hydraulic binders. Fuel 78, 153-159 (1999)

4. Bui, D.D.: Rice Husk Ash as a Mineral Admixture for High Performance Concrete. Delft University Press, Delft (2001)

5. Bui, D.D., Hu, J., Stroeven, P.: Particle size effect on the strength of rice husk ash blended gap-graded Portland cement concrete. Cem. Concr. Comp. 27, 357-366 (2005)

6. Hanafi, S., Abo-El-Enein, S.A., Ibrahim, D.M., El-Hemaly, S.A.: Surface properties of silicas produced by thermal treatment of rice husk ash. Thermochim. Acta 37, 137-143 (1980)

7. James, J., Subba-Rao, M.: Reactivity of rice husk ash. Cem. Concr. Res. 16, 296-302 (1986)

8. Rozainee, M., Ngo, S.P., Salema, A.A., Tan, K.G., Ariffin, M., Zainura, Z.N.: Effect of fluidizing velocity on the combustion of rice husk in a bench-scale fluidized bed combustor for the production of amorphous rice husk ash. Bioresour. Technol. 99, 703713 (2008)

9. Taylor, H.F.W.: Cement Chemistry, 2nd ed. Thomas Telford Pub., London (1997)

10. Mehta, K., Monteiro, P.J.M.: Concrete Microstructure, Properties and Materials, 3rd ed. McGraw-Hill, New York (2006)

11. Cordeiro, G.C., Toledo Filho, R.D., Tavares, L.M., Fairbairn, E.D.R.: Pozzolanic activity and filler effect of sugar cane bagasse ash in Portland cement and lime mortars. Cem. Concr. Compos. 30, 410-418 (2008)

12. Studinka, J.B.: Asbestos substitution in the fibre cement industry. Int. J. Cem. Lightweight Concr. 11, 73-78 (1989)

13. Coutts, R.S.P.: Wood fibre reinforced cement composites. In: Swamy, R.N. (ed.), Concrete Technology and Design, vol. 5: Natural Fibre Reinforced Cement and Concrete, pp. 1-62. Blackie and Son Ltd, London (1988)

14. MacVicar, R., Matuana, L.M., Balatinecz, J.J.: Aging mechanisms in cellulose fiber reinforced cement composites. Cem. Concr. Compos. 21, 189-196 (1999)
15. Toledo Filho, R.D., Ghavami, K., England, G.L., Scrivener, K.: Development of vegetable fibre-mortar composites of improved durability. Cem. Concr. Compos. 25, 185-196 (2003)

16. Yu, Q., Sawayama, K., Sugita, S., Shoya, M., Isojima, Y.: The reaction between rice husk ash and $\mathrm{Ca}(\mathrm{OH}) 2$ solution and the nature of its product. Cem. Concr. Res. 29, 37-43 (1999)

17. Goldman, A., Bentur, A.: The influence of microfillers on enhancement of concrete and strength. Cem. Concr. Res. 23, 962-972 (1993)

18. Luxán, M.P., Madruga, F., Saavedra, J.: Rapid evaluation of pozzolanic activity of natural products by conductivity measurement. Cem. Concr. Res. 19, 63-68 (1989)

19. Allen, T., Marshall, K.: The Electrical Sensing Zone Method of Particle Size measurement. The Coulter principle. University of Bradford, England (1972)

20. Campbell, M.D., Coutts, R.S.P.: Wood fibre-reinforced cement composites. J. Mater. Sci. 15, 1962-1970 (1980)

21. Toledo Filho, R.D., Silva, F.A., Fairbairn, E.M.R., Melo Filho, J.A.: Durability of compression molded sisal fibre reinforced mortar laminates. Construct. Build. Mater. 23, 2409-2420 (2009)

22. Mohr, B.J., Biernacki, J.J., Kurtis, K.E.: Supplementary cementitious materials for mitigating degradation of kraft pulp fibercement composites. Cem. Concr. Res. 37, 1531-1543 (2007)

23. RILEM Technical Committee 49 TFR: Testing methods for fibre reinforced cement-based composites. Mater. Construct. 17, 441456 (1984)

24. Winslow, D.N., Lovell, C.W.: Measurements of pore size distribution in cements, aggregates and soils. Powder Technol. 29, 151-165 (1981)

25. Stroeven, P., Hu, J., Koleva, D.A.: Concrete porosimetry: aspects of feasibility, reliability and economy. Cem. Concr. Comp. 32, 291-299 (2010)

26. Diamond, S.: Mercury porosimetry; an inappropriate method for measurement of pore size distributions in cement-based materials. Cem. Concr. Res. 30, 1517-1525 (2000)

27. Rodrigues, C.S., Stroeven, P., Ghavami, K.: Assessment by law of mixtures approach of interfacial adhesion strength in cellulosecement composites. In: Brandt, A.M., Olek, J., Marshall, I.H. (ed.) International Symposium on Brittle Matrix. Composites, Warsaw, vol 9, pp 71-80, 25-28 Oct 2009

28. Brown, P.H., Shy, D., Skalny, J. Porosity/permeability relationships. In: Skalny, J., Mindess, S. (ed.) Materials Science of Concrete II, pp. 73-109. The American Ceramic Society Inc., Westerville (1991)

29. Rodrigues, C.S., Ghavami, K., Stroeven, P.: Porosity and water permeability of rice husk ash-blended cement composites reinforced with bamboo pulp. J. Mater. Sci 41, 6925-6937 (2006) 